\title{
CULTURAL INTELLIGENCE OF FOREIGN LANGUAGE LECTURERS: A MEASUREMENT TOWARDS GLOBAL COMPETENCE
}

\author{
Devina* \\ Language Center, Faculty of Humanities, Bina Nusantara University \\ Jl. Kemanggisan Illir III No. 45, Kemanggisan, Palmerah, Jakarta 11480, Indonesia \\ devina005@binus.ac.id
}

Received: 03 ${ }^{\text {rd }}$ March 2021/Revised: $20^{\text {th }}$ June 2021/Accepted: $22^{\text {nd }}$ June 2021

How to Cite: Devina. (2021). Cultural intelligence of foreign language lecturers:

A measurement towards global competence. Lingua Cultura, 15(1), 101-108. https://doi.org/10.21512/lc.v15i1.7100

\begin{abstract}
The research measured the cultural quotient (CQ) of foreign language lecturers at Bina Nusantara University. Two major research strategies were applied: (1) a qualitative approach through the interview, and (2) a quantitative approach through $C Q$ scale measurement. Firstly, the CQ scale developed by Ang et al. was tested on ten lecturers. Modifications were made to some test items to suit the context of foreign language teaching. Through the questionnaire, the analysis shows the mean and standard deviation of the overall test at $M=5,19$ and $S D=1,7$. For each domain of the scale, the analysis indicates that $M=$ 5,16 and $S D=1,75$ occurs for metacognitive domain, $M=4,4$ and $S D=1,57$ occurs for cognitive domain; $M=5,4$ and $S D$ $=1,6$ occurs for motivational domain; and $M=5,5$ and $S D=1,8$ occurs for behavioral domain. Among ten lecturers, eight lecturers are considered to have high $C Q$, one lecturer to be medium $C Q$, and one lecturer to be low $C Q$. A further bivariate correlation analysis is then conducted to see the relationship between $C Q$ lecturer's background. The statistical data indicates no significant correlation found between $C Q$ results and lecturer's age $(r=-0,575)$, time spent living abroad $(r=-0,862)$, and time spent for teaching foreign language $(r=-0,644)$. However, the further interview reveals that the experience of having relatives in a foreign country and living in a diverse cultural group shape lecturers' paradigm in language teaching.
\end{abstract}

Keywords: cultural intelligence scale, cultural quotient, foreign language teaching

\section{INTRODUCTION}

The concept of Cultural Quotient (CQ) is introduced by Earley and Ang (2003) to the social science and management field of study. The term serves to define the human ability to retrieve, comprehend, and respond appropriately in any given cross-cultural situation. It is worth noted that by the time the term comes up to air, the world is facing conflict and clashes in the context of culture. Hence, intelligence arises to bridge the effectiveness of interacting among cultures.

Seen as important as Emotional Intelligence (EQ) and Cognitive Intelligence (IQ), CQ is defined as one of the key components' humans need to possess in response to globalization. Ang et al. (2007) have addressed CQ as the intelligence to come as 'effective' in vibrant cross-cultural occasions. The term is rather seen differently with the general EQ and IQ, as CQ deals with the practicality to perform a successful interaction.
Starting from its first development, research has indicated two focuses of CQ; social science (Ang et al., 2007) and international business management (Thomas et al., 2008). The two fields put different approaches in terms of measuring, evaluating, and discussing CQ. Further, both streams applied different testing scales to measure an individual's CQ. However, the CQ scale developed by Ang et al. (2007) gets more popularity for its application flexibility to be applied to various fields of study, such as the empathy dimension (social and emotional) (Mavrou \& Dewaele, 2020; Pawlicka, Kazmierczak, \& Jagiello-Rusilowski, 2019), in which social and emotional closeness (being friendly) is greatly influenced by a high CQ. Recent research on CQ draws on the exploration and application of CQ in several dimensions such as sales education (Delpechitre \& Baker, 2017), entrepreneurial and international performance (Şahin \& Gürbüz, 2017), cultural transmission (Whiten, 2017), transnational aging culture (Sampaio, 2020), social and asocial 
learning mechanism (Miu \& Morgan, 2020), organizational health (Velarde et al., 2020), business opportunity, relativism, and customer relationship performance (Lorenz et al., 2020), and expatriate career performance (Ren, Chadee, \& Presbitero, 2020). Considering what varieties CQ brings about, this present research focuses on the stake of CQ in foreign language learning.

During the first decade since its inception, research topics in CQ mostly explore concepts and practices in work experience and the cross-cultural context in management. It is not until 10-year after the first development that CQ research starts to evoke the depth of this intelligence related to language competence, other intelligence (emotional and social), and education (Rachmawaty et al., 2018; Hong et al., 2019; Wu and Ng, 2020; Senel, 2020; and Jurásek and Potocký, 2020). Such topics bring to discussions are exploring the association between CQ and cross-cultural situations. Rachmawaty et al. (2018) have looked at the correlation between language proficiency (EFL) and strategy for learning in a crosscultural context in Indonesia. The instrument used is TOEFL-like (prediction) test for testing materials. Correlation identifies between strategies for learning (i.e., metacognitive domain M 3,080); however, the research claims no further and significant relationship occurs between learning strategy, proficiency level, and cultural intelligence. From the four CQ scale domains by Ang et al. (2003), the research has further noted that advanced learners take cultural metacognition (understanding of culture) and cognitive knowledge, while novice learners take mostly motivational and behavioral domains for learning contributions.

While mainly the research on CQ development that Ang et al. (2007) or Thomas et al. (2008)'s frameworks, and Hong et al. (2019) explore a new perspective into CQ by David Livermore. The model of CQ focuses on motivation, cognition, metacognition, and behavior domain. The research aims to measure and analyze the freshmen student's cultural intelligence. The score would be used to decide and develop cross-cultural skills in the curriculum. Data are gathered through 123 freshmen students, analyzed, and measured through the CQ scale focusing on drive, knowledge, strategy, and action. The data are treated through correlation analysis. It is found out that the result of CQ is considered to be low. The research tries to find a correlation between male and female students, which shows that female students' CQ is higher than males. The research further confirms that more complex programs are needed for CQ development, and crosscultural intelligence does not merely develop through constant cross-cultural contexts.

$\mathrm{Wu}$ and $\mathrm{Ng}$ (2020) have investigated not only the CQ scale but also the behavior of avoidance, voice behavior, task performance, and the correlation between $\mathrm{CQ}$ and language competency in the multicultural group of 81 business students in Singapore. Students are divided into 14 groups to create a film of cross-cultural conflict in an organization. The whole interaction takes 12 weeks to complete. During the group project, three questionnaires are given: CQ scale, avoidance measurement, and task performance measurement. The measurements that no major influence occurs for $\mathrm{CQ}$ and language competence, yet those with higher $\mathrm{CQ}$ and foreign language competency tend to maintain continuous contact with a diverse cultural group compared to those with low CQ. Further, the study revealed that behavior of avoidance influenced task performance and voice behavior negatively.

In accordance with foreign language learning and bilingualism, Jurásek and Potocký (2020) have looked at the relationship between students' bilingualism, foreign language competence, and cultural intelligence. They investigate such a relationship from 243 undergraduate students in the Czech Republic. Through SmartPLS-SEM 3, it is proved that there has been a positive correlation between cultural intelligence and foreign language competency, yet no positive correlation refers to students' bilingualism. Data show that being either monolingual or bilingual does not relate to cultural intelligence.

Senel (2020) has explored the notion of CQ from students of French, English, and German Department. The research has tried to look at the connection among students' age, department, gender, and CQ. The research involves 200 high school students (166 females and 34 males) in Turkey. Cultural intelligence raises significantly as students participate in intercultural program participation, exchange programs, and interact with people from different cultures. Regarding the role of gender and age to $\mathrm{CQ}$, this research confirms that there is no correlation found, yet those who are 20-22 years perform more intelligence than their younger peers.

Regarding teacher education, Porto (2019) has come up with research on teachers' cross-cultural citizenship and learners' engagement. This research examines 120 students of English teacher education and 30 students of foreign language in Argentina. Data are gathered through classroom activities such as posters, videos, and interviews. This research also takes the data from students' conversations through Skype recorded dialogue, chats, emails conversation, and Facebook posts. This data contributes to a great number of the corpus of words likely to be used in an intercultural context. It is concluded that student teachers are having difficulty understanding intercultural knowledge while developing and teaching intercultural knowledge takes much time. In the place where Argentina has developed its national curriculum, embedding intercultural values inside the learning seems to be not in line with democratic citizenship.

These researches present how CQ is assessed and how far it could reveal the domain inside the scale and its relationship to other factors. Such research proves that there is no correlation between $\mathrm{CQ}$ and foreign language competence (Rachmawaty et al., 2018). However, other researches indicate that correlation occurs for not merely the mastery of 
other foreign languages, but also gender, motivation, behavior avoidance, and task performance (Hong et al., 2019; Wu and Ng, 2020; Senel, 2020; and Jurásek and Potocký, 2020). The negative correlation may be caused by the less-ideal situation between CQs and the research instrument viewed from either the students who have limited experience in the cross-cultural situation or generalization in language learning (i.e., standardized test as the objectives for learning).

After all, the notion of culture always goes together with language learning in various situations (Kramsch, 2013); hence, research on the complexity of culture, cultural intelligence, and the way teaching language has always been a discipline to look at in foreign language learning. Kramsch (2013) has highlighted those issues in the classroom arise as institutions rely on Native Speaker (NS) lecturers. While depending on the authenticity that the NS lecturer brings. Often, NS lecturers are not equipped with adequate knowledge of the local cultures or practices of the students. In contrast, non-NS lecturers know the appropriate techniques and strategies for learning yet lack cultural knowledge. However, this research does not compare non-NS and NS lecturers but rather emphasizes the important role of NS lecturers in foreign language teaching - for their direct relationship with the target language. Kramsch (2013) has addressed that the most common situation in any institution is that NS lecturers are significantly special for providing the 'authentic' target language but lack local cultural wisdom. Thus, when NS lecturers are equipped with adequate culture or are 'intelligent' for their cultural perspective, ideally, adequate learning will be presented. Drawn from the idea of culture in language learning and CQ in foreign language teaching, there are two research questions to be unraveled; how the CQ measurement scale portrays the BINUS foreign language lecturers' CQ capability; and to what extent lecturer's prior knowledge and background influence $\mathrm{CQ}$ results.

Ang et al. (2007) have considered the cultural approach and hence developed the scale of four domains: metacognitive, cognitive, motivational, and behavioral domains. The domains are originally referred to Stenberg's intelligence framework. It is further explained that metacognitive intelligence aims to understand the way humans structure and retrieve knowledge. In cognitive intelligence, the scale focuses on how humans maintain and defend perceived knowledge. This is the phase where questions for a person's intellectual capabilities usually arise. Motivational intelligence aims for the cerebral ability to maintain desire in a given cultural situation. It is the ability to stand for practicality. The behavioral intelligence scale measures the actions that a person does from the situation. Looking at the way the scale is developed, it is worth noted to highlight that the scale is built from the way a person be in the situation (metacognitive), try to understand the knowledge (cognitive), maintain the comprehension (motivational), and react to a specific cultural situation (behavioral). All of them are considered as what Ang et al. (2007) have called as being 'multidimensional'. Then, it could be concluded that the scale tries to measure the thinking process, the depth of one's thoughts, and how the reaction is carried out.

On the one hand, Thomas et al. (2008) developed the CQS into three domains. First is cultural knowledge, where the general and procedural knowledge on cross-cultural interaction. Cultural knowledge aims to measure the general understanding of a certain culture (i.e., traditions) and procedural understanding (i.e., problem-solving) in a specific culture. The second is skills; it is the ability to react learn continuously from cross-cultural interaction. Thomas et al. (2008) have divided the skills into three sub-domains; perceptual skills - having the critical perspective on cultural differences; relational skills - having the ability to perform applicable attitudes (e.g., empathy, reliability); adaptive skills - having the ability to not only solely take the idea of the other culture but create such bridge (adjust) between one and others. The third is cultural metacognition - a goal for being conscious aiming for effective self-regulation and monitoring.

Both scales by Ang et al. (2007) and Thomas et al. (2008) have tried to define and measure CQ by setting several domains. Ang et al. (2008) have set the domains for metacognitive, cognitive, behavioral, and motivational, while Thomas et al. (200) have set the domains for cultural knowledge, skills, and metacognition. Table 1 and 2 display some sample items taken from both sources.

Table 1 CQS by Thomas et al. (2008)

\begin{tabular}{ll}
\hline \multicolumn{1}{c}{ Domain } & \multicolumn{1}{c}{ Questionnaire Sample Items } \\
\hline Cultural Knowledge & \\
- Content & $\begin{array}{l}\text { I know that in general, Americans } \\
\text { enjoy and Chinese dislike } \\
\text { adversarial debate. }\end{array}$ \\
- Process & $\begin{array}{l}\text { I know that my attitudes and those } \\
\text { of others toward specific behavior } \\
\text { influenced by cultural norms and } \\
\text { values }\end{array}$
\end{tabular}

Cultural Skills

(Perceptual, relational, adaptive) my tendency, as an American to debate when in a culture that considers it to be negative)

\section{Cultural Metacognition}

(Monitoring, regulation)

I actively reflect on available knowledge and skills regarding debate, how these relate to desired outcomes, in a cross-cultural setting to formulate alternative courses of action. 
Table 2 QS by Ang et al. (2007)

\begin{tabular}{ll}
\hline \multicolumn{1}{c}{ Domain } & \multicolumn{2}{c}{ Questionnaire Sample Items } \\
\hline Metacognitive & $\begin{array}{l}\text { I am conscious of the cultural } \\
\text { knowledge I use when interacting } \\
\text { with people with different cultural } \\
\text { backgrounds. }\end{array}$ \\
Cognitive & $\begin{array}{l}\text { I know the legal and economic systems } \\
\text { of other cultures. }\end{array}$ \\
Motivational & $\begin{array}{l}\text { I enjoy interacting with people from } \\
\text { different cultures. }\end{array}$ \\
Behavioral & $\begin{array}{l}\text { I change my verbal behavior (e.g., } \\
\text { accent, tone) when a cross-cultural } \\
\text { interaction requires it. }\end{array}$ \\
\hline
\end{tabular}

The discussion of the CQ scale digs deeper into revealing some other domains for the scale (Bücker, Furrer, \& Lin, 2015). The research argues that although the recent scale is considered to have multidimensional while measuring CQ, it does not truly assess the validity of discrimination and the background of the test-taker. There is no indication of test items questioning the test taker's experience. It is common for the CQ test to be given to inexperienced test-takers who have not experienced cross-cultural interaction beforehand or had limited cross-cultural encounters. Some tests are for the 'culturally experienced' users as well; however, the number is limited. While most CQ tests are given to the inexperienced test-taker, the notion of being 'experienced' from the validity scale of 1 to 7 has been considered unclear. This finding contradicts Ang et al. (2007), who develop the CQ scale as they suggest that the test be robust and clear. Bucker, Furrer, and Lin (2015) have added 'psychometric properties' to the scale so that it may reveal the depth of previous cultural and cross-cultural experiences. The newly suggested question items are age, gender, education background, time abroad, and contact frequency.

Research on testing CQ validity is conducted by Wilson et al. (2017) by looking at the newly resided immigrants in New Zealand. The research involves the adaptation of a sociocultural measurement model, known as the Sociocultural Adaptation Scale (SCAS-R). Unlike the original CQ test, the adaptation scale treasures engagement in community and ecological adaptability of the migrants. Further aspects of being considered are cultural engagement and intelligence, social skills, cross-cultural adjustment, and mental adaptation. The research has suggested that the SCAS-R scale developed is valid while adding other domains (proficiency in a language, mental adaptation, and social cognition). While most CQ scale test measures people within an organization, this research presents how it may be applied for migrants and measures migrants' well-being.

In line with Wilson et al. (2017), Rana, Bhasin, and Mushtaq (2020) have explored cultural intelligence in Indian universities. The research draws back on the fact that the country has been hosting many international students, and cultural intelligence is needed by international personnel to survive in a foreign country. Conducted to the international students taking study in India, the research has suggested that behavioral CQ indicates a positive influence on student's adaptation psychologically.

In the research, the researcher specifically refers to the CQ indicator set by Common Purpose, accessible from https://commonpurpose.org. The website page provides unlimited access for testing CQ, mainly intended for individuals undertaking study or work in a foreign country. While the research does not adapt the parameter for measuring, it takes the indicators for labeling and/or interpreting the CQ results, i.e., low, medium, and high.

\section{METHODS}

This research involves ten language lecturers of IFL. Seven lecturers are teaching other languages as well, such as English, Spanish, and Japanese. The age ranges from 27 to 43 years of age, while the length of teaching varies from three months to 22 years. The first step of the research design applies a qualitative approach. In this step, the CQ scale is distributed through closed questionnaires in which all test items are inverted to the Likert scale $(1-7)$. The CQ scale template took into the research is the test developed by Ang et al. (2007). Adjustments are made to most of the question items so that it is suitable for the context of teaching a foreign language. The example can be seen in Table 3.

Table 3 Original vs. Adjusted CQ Test Items

\begin{tabular}{ll}
\hline \multicolumn{1}{c}{ Original question item } & \multicolumn{1}{c}{ Adjusted question item } \\
\hline I know the cultural value & I know the cultural value \\
and religious belief of other & $\begin{array}{l}\text { and religious belief of my } \\
\text { sulture. }\end{array}$ \\
\hline
\end{tabular}

While the original test item asks the knowledge on 'other cultures', this specific test asks the same degree of understanding on the students. Hence, this is to say that the test aims to see lecturer's prior knowledge of their foreign students as they are teaching. No changes are made to the Likert scale, as the original test applies scale 1 to 7 . In total, there are 20 test items in which each five of them represents metacognitive, cognitive, motivational, and behavioral CQ. While the original test item does not ask about the lecturer's background, this research collects lecturers' background data, i.e., age, length of teaching, types of the institution for teaching, and gender. By doing so, this research would like to see whether those backgrounds influence the way CQ is acquired.

After all, questionnaires have been collected; it is soon calculated. A further qualitative data is gathered through interviews conducted with two lecturers. 
This aims at exploring the experience, adjustment, and story of cultural adaptation made throughout their teaching journey. The combinations from both quantitative results (questionnaire) and qualitative data (interview) are then used as the resources for this research. Figure 1 depicts the research road map. A further SPSS analysis is conducted to identify the mean (M), standard deviation (SD), and bivariate correlation among variables. Here, the bivariate correlation fundamentals to know whether there is any significant correlation from age, prior duration spent living abroad, and length of time teaching a foreign language to the $\mathrm{CQ}$ result.

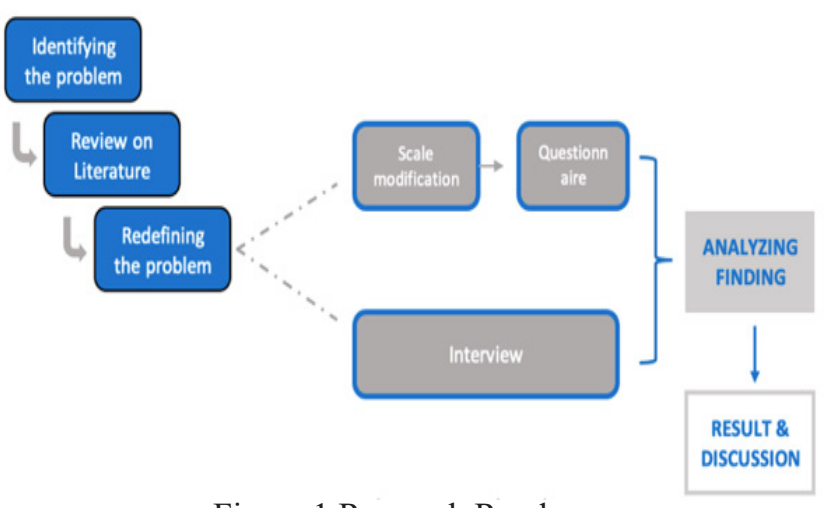

Figure 1 Research Roadmap

\section{RESULTS AND DISCUSSIONS}

Having tested the scale to lecturers of foreign languages, the data shows the following findings. The overall CQ scale test shows $\mathrm{M}=5,19$ and $\mathrm{SD}=1,7$. For each domain, the Ms and SDs are (1) metacognitive domain $\mathrm{M}=5,16, \mathrm{SD}=1,75$; (2) cognitive domain $\mathrm{M}=4,4$ and $\mathrm{SD}=1,57$; (3) motivational domain $\mathrm{M}$ $=5,4, \mathrm{SD}=1,6$; and (4) behavioral domain $\mathrm{M}=5,5$, $\mathrm{SD}=1,8$

For each lecturer, $\mathrm{M}$ are found to be 2,$1 ; 4,4$; 5,$3 ; 5,5 ; 5,4 ; 5,9 ; 6,2 ; 5,5 ; 5,2 ;$ and 5,8 . These number are then referred to the indicators of CQ scale by Common Purposes - a source for testing CQ. Three labels are given to the scale; $0-2,3=$ low; $2,4-4,6=$ medium; and 4,7 $-7=$ high. Data in Table 4 shows that one lecturer has low CQ, one lecturer has medium CQ, while the rest eight lecturers have high CQ.

More into this, bivariate correlation analysis is conducted to know whether the variables of age, time spent living abroad, and time spent prior to teaching foreign language relate to the CQ result. On the variable of age, there is no significant correlation indicated for the CQ result, as the data shows that $\mathrm{r}=$ $-0,575$ (Figure 2).

Figure 3 shows there is no significant correlation indicated for CQ results, $r=-0,862$ for the variable of prior time spent for living abroad.

Table 4 CQ Result

\begin{tabular}{ccccccc}
\hline Lecturer & $\begin{array}{c}\text { Time spent living } \\
\text { abroad *months }\end{array}$ & Age & $\begin{array}{c}\text { Time spent prior to teaching } \\
\text { foreign language *months }\end{array}$ & Mean & Std. Deviation & CQ result \\
\hline L1 & 120 & 43 & 264 & 2,150 & 0,671 & Low \\
L2 & 0 & 28 & 36 & 4,400 & 1,273 & Medium \\
L3 & 24 & 27 & 48 & 5,350 & 2,360 & High \\
L4 & 0 & 34 & 84 & 5,550 & 1,820 & High \\
L5 & 0 & 29 & 4 & 5,450 & 0,686 & High \\
L6 & 0 & 36 & 132 & 5,950 & 0,224 & High \\
L7 & 14 & 29 & 72 & 6,200 & 1,281 & High \\
L8 & 4 & 38 & 15 & 5,500 & 1,877 & High \\
L9 & 0 & 31 & 6 & 5,200 & 0,834 & High \\
L10 & 9 & 27 & 96 & 5,850 & 1,348 & High \\
\hline
\end{tabular}

\section{Correlations}

\begin{tabular}{llr|r} 
& & \multicolumn{1}{c}{ Age } & CQ Result \\
\hline \multirow{2}{*}{ Age } & Pearson Correlation & 1 & -.575 \\
\cline { 2 - 4 } & Sig. (2-tailed) & & .082 \\
\cline { 2 - 4 } & $\mathrm{N}$ & 10 & 10 \\
\hline \multirow{2}{*}{ CQ Result } & Pearson Correlation & -.575 & 1 \\
\cline { 2 - 4 } & Sig. (2-tailed) & .082 & \\
\hline & $\mathrm{N}$ & 10 & 10 \\
\hline
\end{tabular}

Figure 2 Correlation Analysis on Lecturers' Age 


\begin{tabular}{|c|c|c|c|}
\hline \multicolumn{4}{|c|}{ Correlations } \\
\hline & & $\begin{array}{l}\text { Time spent } \\
\text { living abroad }\end{array}$ & CQ Result \\
\hline \multirow{3}{*}{$\begin{array}{l}\text { Time spent living } \\
\text { abroad }\end{array}$} & Pearson Correlation & 1 & $-.862^{* *}$ \\
\hline & Sig. (2-tailed) & & .001 \\
\hline & $\mathrm{N}$ & 10 & 10 \\
\hline \multirow[t]{3}{*}{ CQ Result } & Pearson Correlation & $-.862^{* *}$ & 1 \\
\hline & Sig. (2-tailed) & .001 & \\
\hline & $\mathrm{N}$ & 10 & 10 \\
\hline
\end{tabular}

Figure 3 Correlation Analysis on Lecturers' Time Spent Living Abroad

Regarding the variable of length of foreign language teaching experience, there is no significant correlation occur for CQ results, $r=-0,644$ (Figure 4).

\begin{tabular}{|c|c|c|c|}
\hline \multicolumn{4}{|c|}{ Correlations } \\
\hline & & $\begin{array}{l}\text { Time } \\
\text { spent for } \\
\text { teaching } \\
\text { foreign } \\
\text { language }\end{array}$ & CQ Result \\
\hline \multirow{3}{*}{$\begin{array}{l}\text { Time spent for teaching } \\
\text { foreign language }\end{array}$} & Pearson Correlation & 1 & $-.644^{*}$ \\
\hline & Sig. (2-tailed) & & .045 \\
\hline & $\mathrm{N}$ & 10 & 10 \\
\hline \multirow[t]{3}{*}{ CQ Result } & Pearson Correlation & $-.644^{*}$ & 1 \\
\hline & Sig. (2-tailed) & .045 & \\
\hline & $\mathrm{N}$ & 10 & 10 \\
\hline
\end{tabular}

$\because$ Correlation is significant at the 0.05 level (2-tailed).

Figure 4 Correlation Analysis on Time Spent for Teaching Foreign Language

Further research is conducted through interviews with two lecturers (as a sample) with the intention to reveal stories, practices, and beliefs throughout their teaching journey. The interviews are conducted for test-taker 5 and test-taker 3, in which both of them are regarded to have high CQ.

Lecturer 5 believes in the idea of bringing intelligence of culture into the classroom. While teaching Indonesian as a Foreign Language (IFL) for business communication to the Dutch students, it is noted that she perceives and acknowledges some jokes, jargon, and general culture in the Netherlands. To this sense, lecturer 5 draws on this knowledge and uses it as a bridge or way of building interaction inside the classroom. Mainly, it is said that when students get bored or seem to be a little unenthusiastic, this knowledge of the jokes helps the lecturer to bring back the environment for learning. It is admitted that students are surprised knowing their lecturer jokes about the same thing with students' background. While lecturer 5 receives knowledge from having relatives in the Netherlands, lecturer 5 has never lived there. It is also worth to note that lecturer 5 has never lived abroad. On the discussion to be intelligent culturally, lecturer 5 believes that general knowledge on students' background helps to understand characteristics of the students, as well as a means of appreciating students for who they are. While students are learning Indonesian, this does not necessarily mean that they have to take off their own culture. By noting such differences and similarities in practices and beliefs, students' language acquisition tends to be easier to achieve since students rely on their individual experience.

For lecturer 3, being culturally intelligent means to note the global culture. That is to say that students need to know their own, the target language, and global culture. The courses that lecturer 3 teaches are Introductory Indonesian, Indonesian Newspaper Reading, and Indonesian for Business Communication, which is taught for foreigners. Questions as 'How about your culture?' or 'What happens in your country?' are often shared by lecturer 3 in the classroom. The idea is to note differences, and no single culture is greater than the others. Together, they will draw on the global culture to notice what happens outside students' culture and target language. Lecturer 3 believes that by learning other languages, students can also draw on the world's knowledge. Hence, lecturers need to get exposed to other cultures so that it is easier for them to share stories throughout the learning.

Regarding the research questions, this part will answer the questions. First, how does the CQ measurement scale portray the lecturers of a foreign language? Among ten foreign language lecturers from Bina Nusantara, eight lecturers are regarded to have high $\mathrm{CQ}$, one lecturer is regarded as having medium, and one lecturer is indicated to have low CQ. Second, to what extent do lecturers' prior knowledge and background influence their CQ results? While the second research questions aim at revealing the relationship of lecturer's background with their CQ result, statistical data through bivariate correlation does not portray any relationship (variable age $r=$ $-0,575$; variable time spent living abroad $\mathrm{r}=-0,862$; variable prior experience teaching foreign language $r=$ $-0,644)$. However, the interview reveals more insights into several factors. While lecturer 5 has never been abroad, he/she receives foreign (Dutch) knowledge from the relative, in which it is used the classroom. Lecturer 3 lived in the US for almost two years, in which she adapts to a diverse culture, causing lecturer 3 to continuously looks for global mindset objectives in learning.

Although statistically reported that there is no significant correlation between lecturers' prior background to their CQ result, the relationship happens 
for other factors. Hence, it will be best to evaluate CQ through a combination of qualitative and quantitative data. The questionnaire result also reveals that higher CQ scores go for lecturers who possess no experience of living abroad. More measurements need to be done on lecturers with more than 10-year of experience living abroad. A low CQ score is being displayed by lecturer 1, who has spent ten years living abroad. Compared to the other lecturers who have not spent that much time living abroad. Previously, it is assumed that lecturer 1 receives a higher CQ score as lecturer 1 has the experience of being opened up to other cultures for a decade. On the other hand, four lecturers who have not been living abroad show higher CQ results. It is apparent that the result is not in accordance with the prior prejudice.

All in all, being culturally intelligent is fundamental for the global citizen. From the point of view of foreign language learners, this would support the way of teaching and materials shared with the students. Lectures shape the students through the teaching materials and their attitudes. Culturally intelligent lecturers are somehow more detached from their own culture and can bring more values and insights from other perspectives. The goal is to make learning-rich. Having the result that eight lecturers in Bina Nusantara have high CQ results means lecturers are mostly adaptive to the world's perspective.

\section{CONCLUSIONS}

The research addresses being culturally intelligent for foreign language lecturers (Indonesian and Spanish) at Bina Nusantara University, Indonesia. In the context of foreign language teaching, culture is always embedded in learning; thus, the lecturers who are open to many cultural practices are more adaptive and may take this into learning. The research is conducted on ten lecturers of foreign language. The CQ test is given through a closed questionnaire. The questionnaire also asks about lecturers' backgrounds such as age, teaching experience, and experience of living abroad. Results of the CQ test are labeled as having low, medium, or high CQ. Among ten lecturers, eight lecturers are regarded as high, one lecturer as a medium, and one lecturer as low CQ. Data on age, the experience of teaching, and living abroad are then analyzed through bivariate correlation. It is further found that no significant statistical correlation is made from the three variables to CQ results. However, further interviews with lecturer 5 and 3 reveal their adaptation and CQ's meaning in the foreign language classroom. As lecturer 5 notes that jokes support the classroom, lecturer 3 identifies global mindset objectives as the learning outcomes.

The research comes without its limitation. Conducted in Indonesia, it tries to see how CQ of foreign language lecturers. Although adjustments are made to the scale, the notion of testing is still referred to the management studies. Thus, further research might develop test questions items intended for foreign language study.

\section{REFERENCES}

Ang, S., Van Dyne, L., Koh, C., Ng, K. Y., Templer, K. J., Tay, C., \& Chandrasekar, N. A. (2007). Cultural intelligence: Its measurement and effects on cultural judgment and decision making, cultural adaptation and task performance. Management and Organization Review, 3(3), 335-371. https://doi. org/10.1111/j.1740-8784.2007.00082.x.

Bücker, J., Furrer, O., \& Lin, Y. (2015). Measuring cultural intelligence (CQ): A new test of the CQ scale. International Journal of Cross-Cultural Management, 15(3), 259-284. https://doi. org/10.1177/1470595815606741.

Delpechitre, D., \& Baker, D. S. (2017). Cross-cultural selling: Examining the importance of cultural intelligence in sales education. Journal of Marketing Education, 39(2), 94-108. https://doi. org $/ 10.1177 / 0273475317710060$.

Earley, P. C., \& Ang, S. (2003). Cultural intelligence: Individual interactions across cultures. California: Stanford University Press.

Hong, J. Y., Ko, H., Mesicek, L., \& Song, M. (2019). Cultural intelligence as education contents: Exploring the pedagogical aspects of effective functioning in higher education. Concurrency and Computation: Practice and Experience, 33(2), e5489. https://doi. org/10.1002/cpe.5489.

Jurasek, M., \& Potocky, T. (2020). Management of innovations in cross-cultural communication within an organization. Marketing and Management of Innovations, 2, 108-121. https://doi.org/10.21272/ mmi.2020.2-08.

Kramsch, C. (2013). Culture in language teaching. Iranian Journal of Language Teaching, 1(1), 87- 75.

Lorenz, M. P., Ramsey, J. R., Andzulis, J. M., \& Franke, G. R. (2020). The dark side of cultural intelligence: Exploring its impact on opportunism, ethical relativism, and customer relationship performance. Business Ethics Quarterly, 30(4), 552-590. https:// doi.org/10.1017/beq.2020.2.

Mavrou, I., \& Dewaele, J. (2020). Emotionality and pleasantness of mixed-emotion stimuli: The role of language, modality, and emotional intelligence. International Journal of Applied Linguistics, 30(2), 313-328. https://doi.org/10.1111/ijal.12285.

Miu, E., \& Morgan, T. J. (2020). Cultural adaptation is maximised when intelligent individuals rarely think for themselves. Evolutionary Human Sciences, 2, 1-18. https://doi.org/10.1017/ehs.2020.42.

Pawlicka, P., Kazmierczak, M., \& Jagiello-Rusilowski, A. (2019). Empathy and social closeness toward refugees from Syria: The mediating role of cultural intelligence. Journal of Community Psychology, 47(5), 1014-1031. https://doi.org/10.1002/ jcop. 22169 .

Porto, M. (2019). Affordances, complexities, and challenges 
of intercultural citizenship for foreign language teachers. Foreign Language Annals, 52(1), 141-164. https://doi.org/10.1111/flan.12375.

Rachmawaty, N., Wello, M. B., Akil, M., \& Dollah, S. (2018). Do cultural intelligence and language learning strategies influence students' English language proficiency? Journal of Language Teaching and Research, 9(3), 655-663. https://doi.org/10.17507/ jltr.0903.27.

Rana, M., Bhasin, J., \& Mushtaq, S. (2020). Measurement of cultural intelligence and its impact on psychological adaptation of international students in India. Vision: The Journal of Business Perspective, 24(4), 452459. https://doi.org/10.1177/0972262920939789.

Ren, S., Chadee, D., \& Presbitero, A. (2020). Influence of informal relationships on expatriate career performance in China: The moderating role of cultural intelligence. Management and Organization Review, 16(3), 569-593. https://doi.org/10.1017/ mor.2020.16.

Şahin, F., \& Gürbüz, S. (2017). Entrepreneurial orientation and international performance: The moderating role of cultural intelligence. Journal of Management \& Organization, 26(2), 263-287. https://doi. org/10.1017/jmo.2017.52.

Sampaio, D. (2020). Languages of othering and cultural hybridity: Transnational cultures of ageing in the context of return to the Azores. Ageing and Society, 41(6), 1289-1307. https://doi.org/10.1017/ s0144686x20001373.

Şenel, M. (2020). Investigation of the cultural intelligence levels of the Turkish university students at foreign language departments. IJOLE: International Journal of Language Education, 4(3), 361-377. https://doi. org/10.26858/ijole.v4i3.14806.

Thomas, D. C., Elron, E., Stahl, G., Ekelund, B. Z., Ravlin, E. C., Cerdin, J., Poelmans, S., Brislin, R., Pekerti, A., Aycan, Z., Maznevski, M., Au, K., \& Lazarova, M. B. (2008). Cultural intelligence: Domain and assessment. International Journal of CrossCultural Management, 8(2), 123-143. https://doi. org/10.1177/1470595808091787.

Velarde, J. M., Ghani, M. F., Adams, D., \& Cheah, J. (2020). Towards a healthy school climate: The mediating effect of transformational leadership on cultural intelligence and organisational health. Educational Management Administration \& Leadership, 174114322093731. https://doi. org/10.1177/1741143220937311.

Whiten, A. (2017). When does cultural transmission favour or instead substitute for general intelligence? Behavioral and Brain Sciences, 40, E222. https:// doi.org/10.1017/s0140525x16001813.

Wilson, J., Ward, C., Fetvadjiev, V. H., \& Bethel, A. (2017). Measuring cultural competencies: The development and validation of a revised measure of sociocultural adaptation. Journal of CrossCultural Psychology, 48(10), 1475-1506. https://doi. org/10.1177/0022022117732721.

Wu, C. P., \& Ng, K. (2020). Cultural intelligence and language competence: Synergistic effects on avoidance, task performance, and voice behaviors in multicultural teams. Applied Psychology. https://doi. org/10.1111/apps.12287. 